\title{
Estimation of the shelf life of pezik pickles using Weibull hazard analysis
}

\author{
Nene Meltem KEKLIK ${ }^{1 *}$, Nursel Develi IŞIKLI ${ }^{1}$, Esen Bilge SUR ${ }^{1}$
}

\begin{abstract}
Beta vulgaris L. var. rapa is a variety of beet with edible dark green leaves and stalks, which is a close relative of Swiss chard. It is widely consumed in central Anatolia region in Turkey due to its high nutritional value and desirable sensory attributes. Locally known as 'pezik', Beta vulgaris L. var. rapa is a highly perishable vegetable. The stalks of pezik are consumed as pickle, allowing longer consumption of this vegetable. In this study, Weibull hazard analysis was applied to the sensory data to determine the shelf life of pezik pickles. The end of shelf life was indicated by the time when $50 \%$ of the panelists found the pickles unacceptable. Pickles blanched for $7 \mathrm{~min}$ and stored at $17-18{ }^{\circ} \mathrm{C}$ were found to have a shelf life of 167 days with $95 \%$ confidence limits of 156-179 days. Prolonged blanching ( 9 min.) decreased the shelf life of pickles by about 19 days.
\end{abstract}

Keywords: Beta vulgaris L. var. rapa; pezik; pickle; shelf life; Weibul hazard analysis.

Practical Application: The production technique presented in this manuscript with the results of shelf life analysis would be a valuable source of information for the researchers and producers interested in pezik pickles, or in general, in traditional or new food products.

\section{Introduction}

Beet (Beta vulgaris) is a plant which belongs to Chenopodiaceae family. Beet has many cultivated varieties, all of which fall into the subspecies Beta vulgaris ssp. vulgaris. Beta vulgaris $\mathrm{L}$. var. rapa is a variety of beet, which is widely grown in the central Anatolia region in Turkey. It has edible dark green leaves and stalks. Locally known as 'pezik', Beta vulgaris L. var. rapa is consumed by local people as stuffings from its leaves and pickles from its stalks.

Green leafy varieties of beet are known to be highly nutritious vegetables. Pezik is a close relative of silver beet or Swiss chard (Beta vulgaris L. var. cicla), which has larger and thicker leaves and stalks compared to pezik. The nutritional profile of silver beet is similar to that of spinach, which contains many phytochemicals and nutrients such as vitamin A (through $\beta$-carotene), vitamin $C$, vitamin $E$, and vitamin B6, and a wide range of minerals including calcium, copper, iron, phosphorus, magnesium, manganese, potassium and zinc (Hedges \& Lister, 2007; Pyo et al., 2004).

Pezik is a highly perishable vegetable. The stalks of pezik, which are thinner and more delicate compared to those of silver beet, are consumed as pickles, thus allowing the consumption of this vegetable for a longer period of time after harvesting. Pezik pickles become ready for consumption after 1.5-2 weeks of fermentation, and can be stored up to one year depending on the storage conditions. Local people prefer to store pezik pickles at room temperature, which, however, reduces the shelf life of the product.
One of the graphical methods to determine the end of shelf life of a food product was introduced by Gacula (1975), which involves staggered sampling design. In this technique, the number of samples that are evaluated increases with storage time. Since all samples belong to the same batch, the product is evaluated throughout the storage period until found unacceptable, and untrained consumers can evaluate the product. This method becomes advantageous over other methods such as 'consumer tests', where batch to batch variability is an issue; and 'team judgement' method, where the evaluation is limited to a team familiar with the product (Cardelli \& Labuza, 2001). This technique was called as "Weibull Hazard Method" by Labuza \& Schmidl (1988) and Fu \& Labuza (1993).

Weibull Hazard method has been used to determine the shelf life of many foods such as luncheon meats (Gacula, 1975), ice cream (Wittinger \& Smith, 1986), cottage cheese (Schmidt \& Bouma, 1992), pasteurized milk (Duyvesteyn et al., 2001), roasted and ground coffee (Cardelli \& Labuza, 2001), concentrated yoghurt (Al-Kadamany et al., 2003), and yayik butter fortified with spice extracts (Arslan et al., 2009).

Although pezik pickles are quite popular in the local area, its commercial production has been quite limited, probably due to the wide domestic production. Therefore, the assessment of the shelf life of pezik pickles would help improve the industrial production of this traditional product. The objectives of this study were to determine the shelf life of traditionally produced pezik pickles by using Weibull Hazard Method and to investigate the effect of blanching time on the shelf life. 


\section{Material and Methods}

\subsection{Production of pezik pickles}

Pezik plant (Figure 1A) was harvested in September from fields and gardens in Sivas region of Turkey. In the production of pezik pickles, local producers generally use the same traditional method with some variation in the ingredients such as spices and their amounts.

In this study, after interviewing with a number of local producers who regularly produce pezik pickles in Sivas, the traditional method described below was selected:

Firstly, the stalks of pezik were separated from the leaves. After washing, the stalks were immersed into boiling water for a period of time until a few stalks could be wrapped around a finger without cracking or losing texture, which indicated the desired texture was obtained. Accordingly, the minimum blanching time was determined to be $7 \mathrm{~min}$. Thus, the stalks were blanched for $7 \mathrm{~min}$, and also $9 \mathrm{~min}$ to determine the effect of blanching time on the shelf life of pezik pickles. Then, the blanched stalks were cooled in water at room temperature. After filtering, $3 \mathrm{~kg}$ of blanched stalks were blended with $100 \mathrm{~g}$ of garlic, $15 \mathrm{~g}$ of red pepper and $68 \mathrm{~g}$ of salt, and placed into a $5 \mathrm{~L}$ glass container. The container was filled up with tap water containing $1.5 \mathrm{~g}$ lemon salt (citric acid)/L. Finally, the lid of the container was closed, and pickles were left to maturation before consumption. Throughout the study, pezik pickles were stored at $17-18{ }^{\circ} \mathrm{C}$. Pezik pickles ready for consumption are shown in Figure 1B.

\subsection{Sensory analysis and determination of $\mathrm{pH}$ and acidity}

The readiness of pezik pickles for consumption was determined by sensory evaluation, $\mathrm{pH}$, and acidity measurements. Sensory analysis was performed by the evaluation of appearance, firmness, odor, taste, and general impression. The sensory properties were scored from 0 (dislike extremely) to 5 (like extremely). Samples of pezik pickles each of $10 \mathrm{~g}$ were served to five panelists, who regularly consumed pezik pickles. Titratable acidity was determined as lactic acid $(\mathrm{g} / 100 \mathrm{~mL})$ according to the method of Cemeroğlu (1992). The $\mathrm{pH}$ measurements were done using a $\mathrm{pH}$ meter (HI 2221, Hanna Instruments, RI, USA). For each blanching time, sensory analysis and $\mathrm{pH}$ and acidity measurements were performed in three paralel. The tests were carried out daily after 5 days following the production of pezik pickles until the day on which the pickles became ready for consumption. The pickles were accepted to be ready for consumption when the samples received at least 3 points for each sensory property, and $\mathrm{pH}$ value dropped below 5.0.

\subsection{Weibull hazard analysis}

Weibull Hazard method is one of the graphical methods used to determine the shelf-life of foods. In this method, the cumulative hazard function of Weibull distribution (Equation 1) is utilized.

$H(t)=\int_{0}^{t} h(x) d x=\left(\frac{t}{\alpha}\right)^{\beta}$

with $H(t)$ as the cumulative hazard function; $h(x)$ as the hazard function; $t$ as time; $\alpha$ as the scale parameter, and $\beta$ as the shape parameter.

When the logarithm of time is plotted against logarithm of cumulative hazard values, resulting graph is linear as shown in Equation 2.

$\log t=\left(\frac{1}{\beta}\right) \log H+\log \alpha$

The shelf life is determined as the time when the cumulative hazard value is equal to $69.3 \%$, which corresponds to $50 \%$ critical probability of failure (Fu \& Labuza, 1997).

\subsection{Determination of the shelf life of pezik pickles using Weibull hazard analysis}

Pezik pickles were evaluated by untrained panelists according to Weibull Hazard analysis model (Cardelli \& Labuza, 2001). The panelists were selected from people who regularly consume pezik pickles. In each test, panelists were asked to label the product as "acceptable" (+) or "unacceptable" (-). The first test started with 3 panelists. The number of panelists was increased by 1 in the following test. However, when the number of unacceptable $(-)$ responses were equal or greater than those of acceptable $(+)$ responses, the number of panelists was further increased by the number of unacceptable (-) responses obtained in the previous test, while the time between the successive tests was decreased by approximately half.

At the end of the storage time, the unacceptable responses were ranked, and the hazard values were calculated by $100 /$ rank.
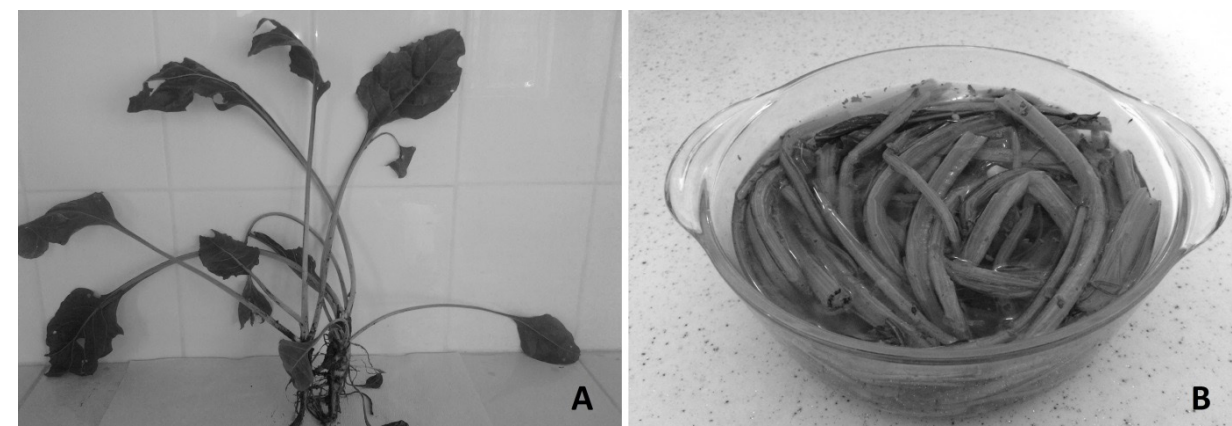

Figure 1. Pezik plant (Beta vulgaris L. var. rapa) (A) and pezik pickles (B). 
Log (cumulative hazard) was plotted versus log (storage time), and the shelf life of pezik pickles was determined as the time when the cumulative hazard value was equal to $69.3 \%$ with confidence limits of 95\% using MINITAB 17 (Minitab Inc., State College, PA, USA). Weibull distribution is unskewed when the value of $\beta$ falls between 2 and 4 (Cardelli \& Labuza, 2001).

\section{Results and Discussion}

Sensory analysis and $\mathrm{pH}$ and acidity measurements indicated that Pezik pickles became ready for consumption on the $10^{\text {th }}$ day of maturation. On this day, the sensory analysis indicated that samples blanched for 7 or 9 min obtained similar sensory scores. While the firmness, apperance and odor were scored as ' 3 ', the taste and general impression were scored as ' 4 '. The $\mathrm{pH}$ values of pickles blanched for 7 and 9 min, which were ready for consumption, were found to be 4.86 and 4.70 , respectively. On the other hand, the values of titratable acidity for pezik pickles blanched for 7 and 9 min were $0.47 \mathrm{~g} / 100 \mathrm{~mL}$ and $0.62 \mathrm{~g} / 100 \mathrm{~mL}$, respectively.

The Weibull sensory data were started to be collected on the $10^{\text {th }}$ day of maturation, i.e. when the pickles were ready for consumption. Weibull sensory data including the responses of sensory panelists and corresponding rank numbers obtained during the storage time for pezik pickles blanched for 7 and 9 min are presented in Tables 1 and 2, respectively.

For pickles blanched for $7 \mathrm{~min}$, the total number of unacceptable (negative) responses in 170 days was 28 , the first of which was observed on the $60^{\text {th }}$ day following the maturation of the pickles. On the other hand, for pickles blanched for $9 \mathrm{~min}$, the total number of unacceptable responses in 150 days was 30 with the first one observed on the $40^{\text {th }}$ day following the maturation of the pickles.

Tables 3 and 4 demonstrate the cumulative hazard values corresponding to the periods of storage time (days), which were calculated according to the sensory data. When all of the cumulative hazard values were plotted against storage time, the shape factors $(\beta)$ calculated as $1 /$ slope were found to be $4.27\left(\mathrm{R}^{2}=0.78\right)$ and $3.90\left(\mathrm{R}^{2}=0.79\right)$ for pickles blanched for $7 \mathrm{~min}$ and $9 \mathrm{~min}$, respectively.

The $\beta$ values found are not or barely in the optimum range $(2-4)$, which indicates that the test was extended beyond the shelf-life, shifting $\beta$ outside its optimum range. In such a case, the data need to be re-plotted up to the cumulative hazard value of 100 (Cardelli \& Labuza, 2001).

Figures 2 and 3 show the plots obtained by using cumulative hazard values up to 100 , which resulted in $\beta$ values of 2.84 and 2.58 for 7 and $9 \mathrm{~min}$, respectively, both falling in the unskewed range. The shelf life, the time when the cumulative hazard value was equal to $69.3 \%$, was determined to be 167 days with 95\% confidence limits of 156-179 days for pickles blanched for 7 min (Figure 2).

The shelf life was found to be 148 days with $95 \%$ confidence limits of 138-159 for pickles blanched for 9 min (Figure 3).

Table 1. Weibull sensory data for Pezik pickles blanched for $7 \mathrm{~min}$.

\begin{tabular}{|c|c|c|c|c|c|c|c|c|c|c|c|c|c|c|c|c|c|c|c|}
\hline Days & \multicolumn{19}{|c|}{ Acceptability } \\
\hline $1^{\star}$ & + & + & + & & & & & & & & & & & & & & & & \\
\hline 20 & + & + & + & + & & & & & & & & & & & & & & & \\
\hline 40 & + & + & + & + & + & & & & & & & & & & & & & & \\
\hline 60 & + & + & + & -27 & -28 & + & & & & & & & & & & & & & \\
\hline 80 & + & + & + & + & + & -26 & + & & & & & & & & & & & & \\
\hline 100 & + & + & + & + & + & -25 & + & + & & & & & & & & & & & \\
\hline 120 & + & + & -23 & + & + & + & -24 & + & + & & & & & & & & & & \\
\hline 140 & + & + & -20 & -21 & + & + & + & -22 & + & + & & & & & & & & & \\
\hline 160 & -13 & + & -14 & -15 & + & -16 & + & -17 & -18 & -19 & + & & & & & & & & \\
\hline 170 & -1 & -2 & -3 & -4 & -5 & + & -6 & -7 & + & -8 & -9 & + & + & -10 & + & + & -11 & -12 & + \\
\hline
\end{tabular}

${ }^{*}$ The first day following the maturation of pickles.

Table 2. Weibull sensory data for Pezik pickles blanched for $9 \mathrm{~min}$.

\begin{tabular}{|c|c|c|c|c|c|c|c|c|c|c|c|c|c|c|c|c|c|c|}
\hline Days & & & & & & & & & Acce & bility & & & & & & & & \\
\hline $1^{\star}$ & + & + & + & & & & & & & & & & & & & & & \\
\hline 20 & + & + & + & + & & & & & & & & & & & & & & \\
\hline 40 & + & + & -30 & + & + & & & & & & & & & & & & & \\
\hline 60 & + & + & + & -28 & + & -29 & & & & & & & & & & & & \\
\hline 80 & + & + & -27 & + & + & + & + & & & & & & & & & & & \\
\hline 100 & -25 & + & + & + & -26 & + & + & + & & & & & & & & & & \\
\hline 120 & + & + & + & -21 & -22 & + & -23 & + & -24 & & & & & & & & & \\
\hline 140 & -14 & -15 & -16 & + & -17 & + & -18 & -19 & -20 & + & & & & & & & & \\
\hline 150 & + & -1 & -2 & -3 & -4 & -5 & -6 & + & -7 & -8 & -9 & + & -10 & -11 & + & -12 & -13 & + \\
\hline
\end{tabular}

*The first day following the maturation of pickles. 
These findings indicate that overblanching for $2 \mathrm{~min}$ decreased the shelf-life of pezik pickles stored at $17-18^{\circ} \mathrm{C}$ by about 19 days.

In food production, blanching is a pre-processing step used for different purposes such as softening the product and inactivating enzymes such as peroxidase, polyphenoloxidases, and phenolase, which adversely affect the quality of a product

Table 3. Weibull Hazard ranking table for Pezik pickles blanched for $7 \mathrm{~min}$.

\begin{tabular}{|c|c|c|c|}
\hline Rank & Days & $\mathrm{H}$ value & $\sum \mathrm{H}$ \\
\hline 28 & 60 & 3.6 & 3.6 \\
\hline 27 & 60 & 3.7 & 7.3 \\
\hline 26 & 80 & 3.8 & 11.1 \\
\hline 25 & 100 & 4.0 & 15.1 \\
\hline 24 & 120 & 4.2 & 19.3 \\
\hline 23 & 120 & 4.3 & 23.6 \\
\hline 22 & 140 & 4.5 & 28.2 \\
\hline 21 & 140 & 4.8 & 32.9 \\
\hline 20 & 140 & 5.0 & 37.9 \\
\hline 19 & 160 & 5.3 & 43.2 \\
\hline 18 & 160 & 5.6 & 48.8 \\
\hline 17 & 160 & 5.9 & 54.6 \\
\hline 16 & 160 & 6.3 & 60.9 \\
\hline 15 & 160 & 6.7 & 67.6 \\
\hline 14 & 160 & 7.1 & 74.7 \\
\hline 13 & 160 & 7.7 & 82.4 \\
\hline 12 & 170 & 8.3 & 90.7 \\
\hline 11 & 170 & 9.1 & 99.8 \\
\hline 10 & 170 & 10.0 & 109.8 \\
\hline 9 & 170 & 11.1 & 120.9 \\
\hline 8 & 170 & 12.5 & 133.4 \\
\hline 7 & 170 & 14.3 & 147.7 \\
\hline 6 & 170 & 16.7 & 164.4 \\
\hline 5 & 170 & 20.0 & 184.4 \\
\hline 4 & 170 & 25.0 & 209.4 \\
\hline 3 & 170 & 33.3 & 242.7 \\
\hline 2 & 170 & 50.0 & 292.7 \\
\hline 1 & 170 & 100.0 & 392.7 \\
\hline
\end{tabular}

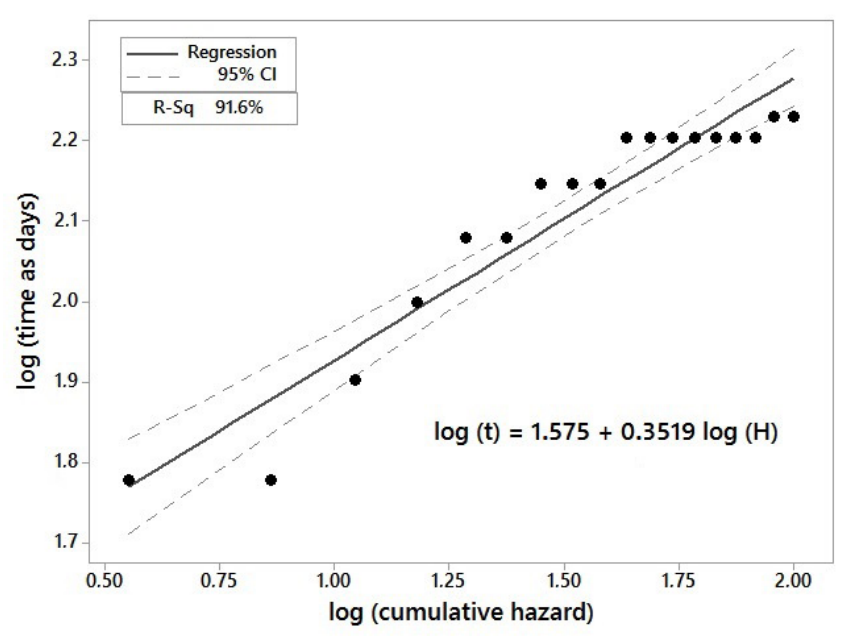

Figure 2. Weibull hazard plot for Pezik pickles blanched for $7 \mathrm{~min}$.
(Wu et al., 2014; Rejano et al., 2007). The purpose of blanching in the production of pezik pickles is to soften the stalks to obtain the desired texture and to stop enzymatic activity that decays vegetables by formation of 'off' color, flavor, and texture during

Table 4. Weibull Hazard ranking table for Pezik pickles blanched for $9 \mathrm{~min}$.

\begin{tabular}{|c|c|c|c|}
\hline Rank & Days & H value & $\sum \mathrm{H}$ \\
\hline 30 & 40 & 3.3 & 3.3 \\
\hline 29 & 60 & 3.4 & 6.8 \\
\hline 28 & 60 & 3.6 & 10.4 \\
\hline 27 & 80 & 3.7 & 14.1 \\
\hline 26 & 100 & 3.8 & 17.9 \\
\hline 25 & 100 & 4.0 & 21.9 \\
\hline 24 & 120 & 4.2 & 26.1 \\
\hline 23 & 120 & 4.3 & 30.4 \\
\hline 22 & 120 & 4.5 & 35.0 \\
\hline 21 & 120 & 4.8 & 39.7 \\
\hline 20 & 140 & 5.0 & 44.7 \\
\hline 19 & 140 & 5.3 & 50.0 \\
\hline 18 & 140 & 5.6 & 55.5 \\
\hline 17 & 140 & 5.9 & 61.4 \\
\hline 16 & 140 & 6.3 & 67.7 \\
\hline 15 & 140 & 6.7 & 74.3 \\
\hline 14 & 140 & 7.1 & 81.5 \\
\hline 13 & 150 & 7.7 & 89.2 \\
\hline 12 & 150 & 8.3 & 97.5 \\
\hline 11 & 150 & 9.1 & 106.6 \\
\hline 10 & 150 & 10.0 & 116.6 \\
\hline 9 & 150 & 11.1 & 127.7 \\
\hline 8 & 150 & 12.5 & 140.2 \\
\hline 7 & 150 & 14.3 & 154.5 \\
\hline 6 & 150 & 16.7 & 171.2 \\
\hline 5 & 150 & 20.0 & 191.2 \\
\hline 4 & 150 & 25.0 & 216.2 \\
\hline 3 & 150 & 33.3 & 249.5 \\
\hline 2 & 150 & 50.0 & 299.5 \\
\hline 1 & 150 & 100.0 & 399.5 \\
\hline
\end{tabular}

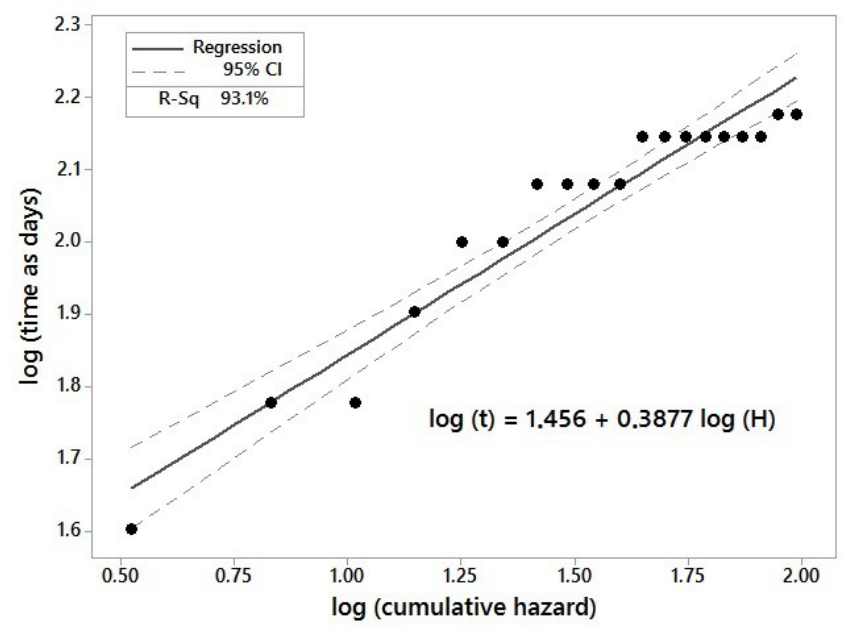

Figure 3. Weibull hazard plot for Pezik pickles blanched for $9 \mathrm{~min}$. 
conservation. However, overblanching, in other words, blanching treatment that is either carried out at a very high temperature or for very long time at a low temperature would result in the loss of texture of vegetables (Ni et al., 2005), which is due to the loss of turgor pressure followed by pectin degradation and solubilization in the cell wall of plant tissues (Dekker et al., 2014; Ma \& Barrett, 2002). Overblanching may adversely affect the quality of vegetables due to loss of nutrients, flavor, color, and freshness (Kim et al., 2015; Erkmen \& Bozoglu, 2016), and thus may shorten the shelf life of vegetables.

For pezik pickles blanched for $9 \mathrm{~min}$, this loss of texture was not evident to cause rejection at the initial periods of consumption. However, probably due to the faster breakdown of the soft tissues by the microorganisms, overblanched pezik pickles were characterized by a shorter shelf-life. Agüero et al. (2005) investigated the effects of blanching on the quality of Swiss chard leaves. Blanching under steam for $30 \mathrm{~s}$ at atmospheric pressure was sufficient to inactivate peroxidase. Longer blanching caused a decrease in sensory attributes of chard leaves such as color, brightness, texture, and overall visual quality.

In our previous study (Biçer et al., 2012), the effect of blanching time on the sensory characteristics of pezik pickles was investigated. The pezik pickles blanched for 9 min generally exhibited lower $\mathrm{pH}$ and higher acidity compared to the pickles blanched for $7 \mathrm{~min}$. This was suggested to be due to longer blanching, which may have allowed the microorganisms to easily ferment the degraded pezik stalks, thus produce more lactic acid. Pezik pickles blanched for 7 and 9 min received a general impression of "slightly disgusting" on the days 160 and 150, respectively. On these days, other sensory characteristics were found to be 'slightly bad' in terms of taste, 'dull yellow-green' in terms of color, and 'soft' in terms of hardness. The acceptable storage time for pezik pickles blanched for 7 or 9 min was comparable to the results obtained in this study by using the Weibull hazard method. These findings indicate that the Weibull hazard method provided a simple approach to the evaluation of shelf life.

\section{Conclusion}

The findings of this study demonstrated that the Weibull hazard method can be considered a reliable model to predict the shelf life of pezik pickles. The blanching time appears to be an important factor affecting the shelf life of pezik pickles. Therefore, it is advisable to select the mimimum required blanching time to lengthen the shelf life of pezik pickles. Otherwise, overblanched pickles, although they may be initially acceptable, will eventually have a shorter shelf life.

\section{Acknowledgements}

We would like to thank Mercan Yanar, Hacer Koç and Feride Keklik for sharing their knowledge and experience with us in the production of pezik pickles.

\section{References}

Agüero, M. V., Pereda, J., Roura, S. I., Moreira, M. R., \& del Valle, C. E. (2005). Sensory and biochemical changes in Swiss chard (Beta vulgaris) during blanching. Lebensmittel-Wissenschaft + Technologie, 38(7), 772-778. http://dx.doi.org/10.1016/j.lwt.2004.07.018.
Al-Kadamany, E., Khattar, M., Haddad, T., \& Toufeili, I. (2003). Estimation of shelf-life of concentrated yogurt by monitoring selected microbiological and physicochemical changes during storage. Lebensmittel-Wissenschaft + Technologie, 36(4), 407-414. http://dx.doi.org/10.1016/S0023-6438(03)00018-5.

Arslan, D., Sert, D., Ayar, A., \& Özcan, M. M. (2009). Shelf life determination of Yayik butter fortified with spice extracts. International Journal of Dairy Technology, 62(2), 189-194. http://dx.doi.org/10.1111/j.14710307.2009.00467.x.

Biçer, E. B., Keklik, N. M., \& Develi Işıklı, N. (2012). The production of pezik pickles and the effect of blanching time on the sensory characteristics. In H. I. Kozan (Ed.), III. traditional foods symposium bulletin book. Konya: Department of Food Engineering, Selçuk University. p. 509-511.

Cardelli, C., \& Labuza, T. P. (2001). Application of Weibull hazard analysis to the determination of shelf life of roasted and ground coffee. Lebensmittel-Wissenschaft + Technologie, 34(5), 273-278. http://dx.doi.org/10.1006/fstl.2000.0732.

Cemeroğlu, B. (1992). Fundamental analysis methods in fruits and vegetable industry (381 p.). Ankara: Biltav Publication.

Dekker, M., Dekkers, E., Jasper, A., Baár, C., \& Verkerk, R. (2014). Predictive modelling of vegetable firmness after thermal pre-treatments and steaming. Innovative Food Science \& Emerging Technologies, 25, 14-18. http://dx.doi.org/10.1016/j.ifset.2013.10.015.

Duyvesteyn, W. S., Shimoni, E., \& Labuza, T. P. (2001). Determination of the end of shelf-life for milk using Weibull hazard method. Lebensmittel-Wissenschaft + Technologie, 34(3), 143-148. http:// dx.doi.org/10.1006/fstl.2000.0736.

Erkmen, O., \& Bozoglu, T. F. (2016). Food preservation by high temperatures. In O. Erkmen \& T. F. Bozoglu (Eds.), Food microbiology: principles into practice (Microorganisms in Food Preservation and Processing, Vol. 2, pp. 21). West Sussex: John Wiley \& Sons. http:// dx.doi.org/10.1002/9781119237860.ch28.

Fu, B., \& Labuza, T. P. (1993). Shelf life prediction: theory and application. Food Control, 4(3), 125-133. http://dx.doi.org/10.1016/09567135(93)90298-3.

Fu, B., \& Labuza, T. P. (1997). Shelf-life testing: procedures and prediction methods. In M. C. Erikson \& Y. C. Hung (Eds.), Quality in frozen food (pp. 377-415). New York: Chapman \& Hall.

Gacula, M. C. (1975). The design of experiments for shelf life study. Journal of Food Science, 40(2), 399-403. http://dx.doi. org/10.1111/j.1365-2621.1975.tb02211.x.

Hedges, L. J., \& Lister, C. E. (2007). Nutritional attributes of spinach, silver beet and eggplant (Crop \& Food Research Confidential Report, Vol. 1928). Christchurch: New Zealand Institute for Crop \& Food Research Limited.

Kim, N. H., Lee, N. Y., Kim, S. H., Lee, H. J., Kim, Y., Ryu, J. H., \& Rhee, M. S. (2015). Optimization of low-temperature blanching combined with calcium treatment to inactivate Escherichia coli $\mathrm{O} 157: \mathrm{H} 7$ on fresh-cut spinach. Journal of Applied Microbiology, 119(1), 139-148. PMid:25816844. http://dx.doi.org/10.1111/jam.12815.

Labuza, T. P., \& Schmidl, M. K. (1988). Use of sensory data in the shelf life testing of foods: principles and graphical methods for evaluation. Cereal Foods World, 33(2), 193-206.

Ma, W., \& Barrett, D. M. (2002). Effects of maturity and processing variables on heat penetration times, firmness and drained weight of diced tomatoes (Halley Bos $3155 \mathrm{cv}$ ). Journal of Food Processing and Preservation, 26(2), 75-89. http://dx.doi.org/10.1111/j.1745-4549.2002. tb00854.x. 
Ni, L., Lin, D., \& Barrett, D. M. (2005). Pectin methylesterase catalyzed firming effects on low temperature blanched vegetables. Journal of Food Engineering, 70(4), 546-556. http://dx.doi.org/10.1016/j. jfoodeng.2004.10.009.

Pyo, Y.-H., Lee, T.-C., Logendra, L., \& Rosen, R. T. (2004). Antioxidant activity and phenolic compounds of Swiss chard (Beta vulgaris subspecies cycla) extracts. Food Chemistry, 85(1), 19-26. http:// dx.doi.org/10.1016/S0308-8146(03)00294-2.

Rejano, L., Sanchez, A. H., Montano, A., Casado, F. J., \& Castro, A. (2007). Kinetics of heat penetration and textural changes in garlic during blanching. Journal of Food Engineering, 78(2), 465-471. http:// dx.doi.org/10.1016/j.jfoodeng.2005.10.016.
Schmidt, K., \& Bouma, J. (1992). Estimating shelf life of cottage cheese using hazard analysis. Journal of Dairy Science, 75(11), 2922-2927. http://dx.doi.org/10.3168/jds.S0022-0302(92)78054-0.

Wittinger, S. A., \& Smith, D. E. (1986). Effect of sweeteners and stabilizers on selected sensory attributes and shelf life of ice cream. Journal of Food Science, 51(6), 1463-1466. http://dx.doi. org/10.1111/j.1365-2621.1986.tb13835.x.

Wu, B., Pan, Z., Qu, W., Wang, B., Wang, J., \& Ma, H. (2014). Effect of simultaneous infrared dry-blanching and dehydration on quality characteristics of carrot slices. Lebensmittel-Wissenschaft + Technologie, 57(1), 90-98. http://dx.doi.org/10.1016/j. lwt.2013.11.035. 